\title{
EL MODO TRANSEÚNTE: LA VIDA ES UN PROCESO INDICIOS PARA UNA NUEVA PEDAGOGÍA
}

\author{
Alejandro Abufom Heresi \\ Universidad de La Serena, Chile. Fono: +56 51 2204368. Correo electrónico: \\ abufom@gmail.com
}

\begin{abstract}
“Tasurinchi, aquel que con sus soplidos amazónicos hizo nacer todo lo bueno y a los indios machiguengas, allá por la selva de Madre de Dios, también ordenó que las tribus caminaran, sin quedarse en sitio fijo, para que el sol no se cayera. Así, los machiguengas fueron huyendo siempre de los peligros, de las enfermedades y todo lo maligno que había enviado Kuntibakori y sus diablillos. Los machiguengas, "los que andan", nunca se asentaron en lugar fijo y permanecieron por siglos libres y de familias ligeras, sin ataduras a los lugares, frugales, atentos y rápidos”
\end{abstract}

"El Hablador", de Mario Vargas Llosa.

El modo transeúnte es aquella actitud que permite no quedarse determinado o fijo en algún estado interno. Cuando uno queda determinado, cuando se queda "pegado" en un estado emocional, intelectual o espiritual, el resultado es siempre el sufrimiento y la pérdida de la libertad para percibir y elegir nuevas opciones.

El modo transeúnte desafía la concepción lineal y telefinalista de la vida que actualmente condiciona toda nuestra cultura. Este paradigma casi absoluto establece una dirección para todos los movimientos y conductas humanas que va de menos a más, de lo peor a lo mejor, de lo malo a lo bueno, de lo insensible a lo sensible, de la pobreza a la riqueza, de lo material a lo espiritual... y así, en todos los órdenes de la vida.

El modo transeúnte: la vida es un proceso... 
El modo transeúnte rompe con la idea de que la vida es un proceso de perfección de cualidades, transformándola en la vivencia de un sinnúmero de estados, que van desde un extremo al otro, pasando por todos sus rangos intermedios.

En la actitud del transeúnte se obtiene el verdadero placer de observar como uno puede desplazarse, con total libertad, entre los aparentes opuestos. Pasar del pensamiento más expansivo a la idea más estrecha; del sentimiento más amoroso a la contracción violenta; de lo grande a lo pequeño; de la incerteza total a la seguridad absoluta; de la contradicción a la perfecta coherencia; de la rigidez mental a la apertura completa... y viceversa, incluyendo todos los estados intermedios.

Pero, ¿qué es lo que diferencia al practicante del modo transeúnte del enfermo esquizofrénico, aquél que se desplaza violentamente en varios estados, o de aquél que no puede establecer con claridad una emoción o un pensamiento, pasando abruptamente y sin control de uno a otro? La diferencia está en que -al asumir el modo transeúnte como actitud de vida- se va adquiriendo:

- Conciencia clara de los procesos que vivencia, al practicar la atención sobre sí mismo.

- La capacidad de elegir los estados, al aprender de sus sutiles mecanismos.

- La sensación de profunda libertad, porque no se identifica permanentemente con ellos como si fueran valores absolutos.

El modo transeúnte es la aceptación de la vida como un continuo existencial, que tiene un sello propio: la conciencia de ese continuo. El modo transeúnte prefiere suponer que lo único permanente y estable es, precisamente, esa conciencia individual sobre los acontecimientos.

Se aparta de la visión del hombre como un ser condicionado a responder a un sinnúmero de impulsos mecánicos y sin sentido, pero tampoco se adhiere a la idea de la vida como un camino que tiene un principio y final deseable que se debe alcanzar, a cualquier precio, para justificar una existencia digna. 


\section{De esta manera:}

- No es necesario ser más inteligente, para ser menos ignorante.

- No es necesario tener más, para dejar de tener menos.

- No es necesario ser más bueno, para dejar de ser malo.

El desarrollo de la vida siempre ha sido visto como un cambio de un estado menor, peor, más estrecho, más bajo, etc., a uno mejor, mayor, más amplio, más alto... Bajo esta concepción, todos los cambios suponen una mejoría, una ganancia, una expansión en relación al estado anterior. Aparece ridículo y sin sentido entonces, cambiar para empeorar, para tener menos, para estrechar las ideas o hasta "involucionar".

¿Pero qué sucede si los cambios son en otra dirección? ¿Qué pasa si escapamos de la linealidad, del ascenso, de la mejoría, si nos apartamos de la idea de una permanente evolución?

¿Qué sucedería si los cambios de un estado a otro son, en sí mismos, los objetivos y la justificación de la vida entera?

¿Qué sucede si el tránsito de un estado a otro es lo más importante, dejando en segundo plano si avanzamos o retrocedemos, ganamos o perdemos, bajamos o subimos?

Bajo esta mirada, será más importante el cómo transitar, en ambas direcciones, entre la sabiduría y la idiotez, por ejemplo, más que aspirar a llegar a un cierto nivel y quedar determinado en ese estado.

Ya no se trataría de ser más inteligente, sabio, adinerado, amoroso o desarrollado, sino de aprender cómo desplazarse entre la inteligencia y la ignorancia, la sabiduría y la estrechez mental, el amor expansivo y el egoísmo total, entre la riqueza y la pobreza.

La vida sería como un experimento constante de conciencia, elección y sentido.

Podríamos vivir la libertad de utilizar nuestros estados de acuerdo a lo requerido por cada situación vital, con flexibilidad y reversibilidad, más allá de una ética unidireccional, estrecha y agobiante. Porque aquél que comprende cómo se producen en sí mismo, los 
cambios de un estado a otro, obtiene la sabiduría de saber cómo conocer, como aprender, como relacionarse, como vivir la vida en toda su maravillosa extensión, sin estar atado a una larga cadena de sucesivos deberes, a un camino predeterminado, con un final predeterminado.

El ser humano se liberaría del miedo implacable de "volver atrás", de perderlo todo, de ser "menos que ayer", de no evolucionar, de no crecer... Y también del miedo al futuro porque el cómo, la operatividad, el tránsito, se viven sólo en el presente.

Puede uno entonces comenzar a vivir con total libertad ya que aprendió como producir el cambio de un estado a otro: lo conoce, lo controla, lo elige, le da sentido, libremente.

La vida comenzaría a tener un sentido obvio, en sí misma, que no necesitaría ser declarado, porque estaría incorporado al individuo como un organismo vivo, por el simple hecho de estar vivo. La vida tendría un sentido en sí misma, como un proceso inagotable de auto-procreación de múltiples estados en un cambio incesante. Los logros y éxitos que tanto agobian al hombre moderno pasarían a ser sólo un cierto tipo de estados, entre muchos otros. Y el aparente fracaso dejaría de producir el dolor que sentimos habitualmente porque lo vivenciaríamos como una etapa más de un devenir inagotable.

Simplemente, pondríamos más atención en el proceso que en los resultados, aprendiendo de nosotros mismos y de los demás, para la próxima experiencia.

El modo transeúnte: la vida es un proceso... 